LA-UR $-86-1781$

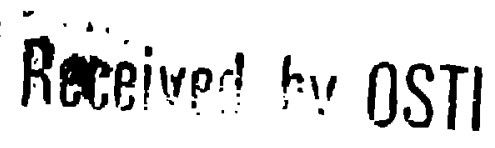

\author{
JUN,$F \quad 30$ \\ C.NF-8LCX150. -
}

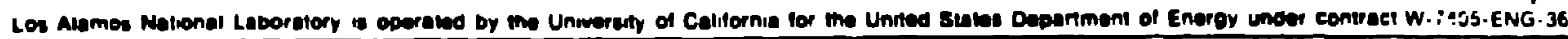

LA-UR--86-1781

DE86 011222

tITLE EXPLRIMENTAL TIIN FILM IDEPOSITION AND SURFACE ANALYSIS TECHNIQUES

aUthor(S) W. Lugene ('oll.l. ns and B. Rambabu

bepartment of lhysics, Southern Inlvereity, Baton Rouge, I.A

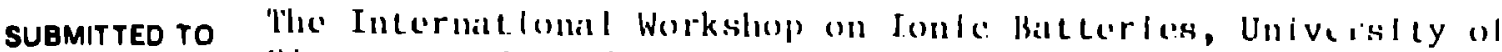
Slap:apore, .Iunc ?--6, 1986

\title{
DISX'I.AIMER
}

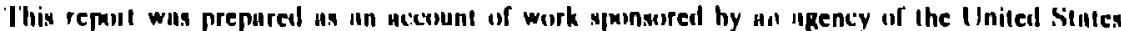

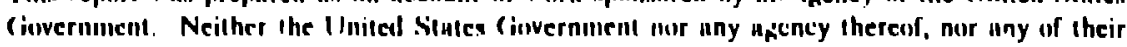

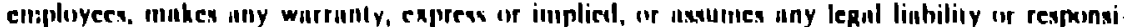

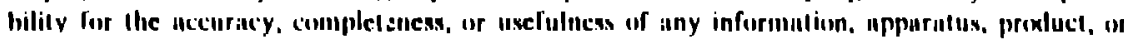

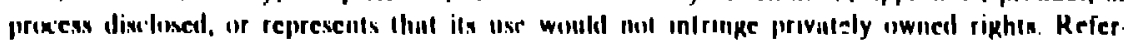

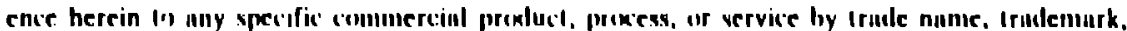

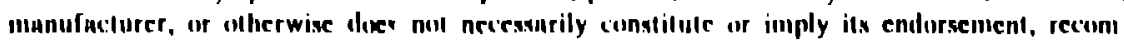

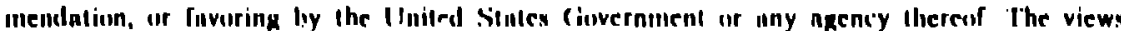
und upinions of authors exprennet herein ilo not necessurily stule or reflect those of the Uniled Sintex (iovernment on any apency therear.
\end{abstract}

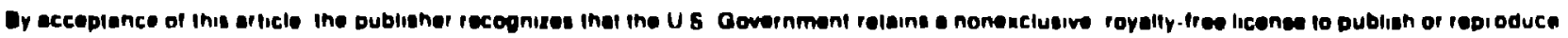
the pubtizhed farm of this coniribution of lo ellom others to do no lor U 5 Oovernment purpones
} 
page $\mathbf{i}$

EXPERIMENTAL THIN FILM DSPOSITION AND SURFACE ANALYSIS TECHNIQUES

\author{
W. Eugene Collins and B. Rambabu \\ Department of Physics \\ Southern University, Baton Rouge, Louisiana- 70813, U.S.A.
}

\title{
1. INTRODUCTION
}

An important concern in the science of superionic conductive materials has been the undertandirg of mechanisms of selectivity for systems ${ }^{1-5}$ with 1) high ionic conductivity $\left[\sim 1 \Omega^{-1} \mathrm{~cm}^{-1}\right]$, 2) low electrical conductivity $\left.\left[\sim 10^{-8}-1 \mathrm{~cm}^{-1}\right], 3\right)$ lit心le temperature dependence of conductivity, 4) low mobile ion equivalent weight, 5) hign decomposition potential, 6) stability with respect to dissociation type reactions, 7) wide temperature range of stability, 8) low specific gravity, 9) conduciveness to electrolyte elements and, 10) Mechanical strength. Much of the primary information on these materials has been obtained from thin films. In the use of solid electrolytes, thin-film forms have practical advantages because their apparent resistance can be reduced. The low internal resistance is especially important in the field of solid state cells for high power and long life operation. So studies of fast ion conduction films have attracted the interest of many research workers beciuse $0_{i}{ }^{\circ}$ their wide applications in both the solid state battery industry and fundamental research. Many papers dealing with preparation and characierization of thin film materials are scattered in the literature ${ }^{1-24}$. Chemical characterizaion of surfices can be done with surface analytical techniques such as ion and photon spectroscopies. The physical characterizations are however often difficult because these surface techniques analyzie only a small area of the surface. Since the surface may be nonuniform, the whole surface should really te analyzed. The aim of this article is to focus attention on differens modern methods of thin film aeposition and experimental tools that have been put to use to unravel the properties of thin fllm materials [ see table 1 ]. 
page 2

It has been shown that it is convenient to classify deposition techniques into two groups: physical and chemical. Physical methods cover deposition techniques which depend on evaporation or sputtering; chemical methods depend on specific chemical reactions. We shall attempt to present methods of thin film deposition and surface analysis techniques with emphasis on the techniques used by the the surface physics laboratory group at Southern University, Baton Rouge, Louisiana, USA.

TABLE 1

RELATIONSHIP OF PROCESS PARAMETERS ON SOME THIN-FILM PROPERTIES ( $X$ INDICATES THE PARTICULAR PROCESS PARAMETER INFLUENCES THE FILM PROPERTY)

\begin{tabular}{|c|c|c|c|c|c|c|c|c|c|c|c|c|}
\hline $\begin{array}{l}\text { PROCE5S } \\
\text { PARAMETER }\end{array}$ & $\begin{array}{cc}S & M \\
U & A \\
B & T \\
S & E \\
T & R \\
R & I \\
A & A \\
: & L \\
E & \end{array}$ & $\begin{array}{ll}\text { S } & C \\
\text { U } & \text { L } \\
B & E \\
S & A \\
T & N \\
R & I \\
A & N \\
T & G \\
E & \end{array}$ & $\begin{array}{cc}S & T \\
U & E \\
E & M \\
S & P \\
T & E \\
R & R \\
A & A \\
T & T \\
E & U \\
& R \\
& E\end{array}$ & $\begin{array}{cc}E & R \\
V & A \\
A & T \\
P & E \\
0 & \\
R & \\
A & \\
T & \\
\text { I } & \\
0 & \\
N & \end{array}$ & $\begin{array}{l}P \\
R \\
E \\
S \\
S \\
U \\
R \\
E\end{array}$ & $\begin{array}{ll}A & I \\
U & 0 \\
X & N \\
V & B \\
A & E \\
P & A \\
0 & M \\
R & \end{array}$ & $\begin{array}{cc}\mathbf{S} & \mathbf{M} \\
\mathbf{T} & A \\
\mathbf{A} & \mathbf{T} \\
\mathbf{R} & \mathbf{E} \\
\mathrm{T} & \mathbf{R} \\
\mathbf{I} & \mathbf{I} \\
\mathbf{N} & \mathbf{A} \\
\mathbf{G} & \mathrm{L}\end{array}$ & $\begin{array}{l}E \\
V \\
A \\
P \\
0 \\
R \\
A \\
T \\
I \\
0 \\
N\end{array}$ & $\begin{array}{l}S \\
P \\
U \\
T \\
T \\
E \\
R \\
I \\
N \\
G\end{array}$ & $\begin{array}{l}S \\
P \\
R \\
A \\
Y \\
I \\
N \\
G\end{array}$ & $\begin{array}{ll}E & D \\
L & E \\
E & P \\
C & 0 \\
T & S \\
R & 1 \\
0 & T \\
& 1 \\
& 0 \\
& N\end{array}$ & $\mathbf{E}$ \\
\hline ADHERENCE & $\bar{x}$ & $\bar{x}$ & $\bar{x}$ & $\bar{x}$ & $\bar{x}$ & $\bar{x}$ & & $x$ & $x$ & $\bar{x}$ & $\bar{x}$ & $\bar{x}$ \\
\hline DEFECTS & $x$ & $x$ & $x$ & & & & $x$ & & $x$ & $x$ & $x$ & $x$ \\
\hline GEOME THICKNF.JS & & $\bar{x}$ & $\bar{x}$ & $\bar{x}$ & $x$ & $x$ & & & $x$ & & & \\
\hline HARDNESS & $\bar{x}$ & $\bar{x}$ & $\bar{x}$ & $\bar{x}$ & $x$ & $\bar{x}$ & & & $x$ & & & \\
\hline TEMP: STABII.ITY & $\bar{x}$ & & $\bar{x}$ & $\bar{x}$ & & $\bar{x}$ & & & & & & \\
\hline STRESS & $x$ & $\bar{x}$ & $x$ & $x$ & $x$ & $x$ & $x$ & & & & & \\
\hline SCATTERING & $x$ & $\bar{x}$ & $\bar{x}$ & $x$ & $x$ & $x$ & $x$ & $x$ & $x$ & $x$ & $x$ & $x$ \\
\hline IN:SOL_UIJ ILITY & & $x$ & $y$ & $x$ & $x$ & $x$ & $x$ & & & & & \\
\hline $\begin{array}{l}\text { PHYYICAL FOHMO: } \\
\text { OF FILM }\end{array}$ & & & & & & & & $\begin{array}{l}1 \\
2\end{array}$ & 2 & 2 & 2 & 3 \\
\hline
\end{tabular}

NOTE: GEVERAL IMPOMIANT ANAI.YTICAL TECINIIQUES IIAVE BFEN UST:D TO STUDY FILM PROPERTIESE SONE AHE i) IRAN:IMIJJION ELLCCIRUN MICROSCOPY(TEM)| 2) SCANNING ELCCTRON MICROSCOPY(SEM)| 3) AUGER ELECTRUN SPICTROSCOPY (AES)| 1) X-HAY PHOTOELECTRON SPECTROSCOPY (XPS)| I) FIELD ION MICROSSCOPY (FIM)| $6, X$ IMAS DITFRACTION (XRU)| 7) REFIEECTED ELLECTRUN DIFFFACTION

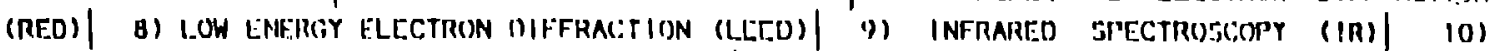
FUURIER TRANSFORM IR SPECTRUSCCPY (FTIH)| II) HILLIPSOMFTRY| (2) OUARTZ CRYSTAL MICROBALANCE (OCMJ)| 13) RETIECTION HIBH ENERGY ELECTRON DIFFRACTIONI) AND 14) ION SCATTERING SPTCTIROSCOPY (IST) 


\section{page 3}

\section{PHYSICAL DEPOSITION METHODS}

\subsubsection{THERMAL EVAPORATION}

Flash evaporation is a modification of the standard thermal evaporation technique. $T$. Minami et al. ${ }^{11}$ grew amorphous glass films of $\mathrm{AgI}-\mathrm{Ag}_{2} \mathrm{MoO}_{4}$ and $\mathrm{AgI}-\mathrm{Ag}_{2} \mathrm{O}-\mathrm{B}_{2} \mathrm{O}_{3}$ when the normal thermal evaporation techniques yielded only crystalline forms. In the flash method, powders

$(<74 \mu \mathrm{m})$ are continuously fed to a heated crucible $\left(>500^{\circ} \mathrm{C}\right)$ in equally small portions. Eacli portion is dropped one after the other and is instantly evaporated, exposing the raw material to high temperature only a short period of time. The time oi exposure of the raw material is the main difference between the standard thermal evaporation method and flash evaporation.

\subsubsection{SPRAYING TECH:IIOUES ${ }^{2}$}

Spraying methods are generally based on the pyrolytic decomposition of Cadmium, Indium and Tin compounds dissolved in a liquid mixiure which is sprayed onto a previously heated substrate. Dawar et al. ${ }^{7}$ have given a review which describes the application of this technique to semiconducting transparert thin films. Pormier ${ }^{13}$ et al. have used a modifled spraying technique to grow films of uniform thickness over a large surface area $(10 \mathrm{~cm} \times 10 \mathrm{~cm})$. The spray nozzle moves in the $X-Y \mu l$ ane above the preheated substrate. A neutral carrier gas (nitrogen) was used and provided very fine drops.

\subsubsection{ELECTRON BEAM EVAPORATION}

Electron beam evaporation is a very common method used in growing films. The basic set-up is snown in figure 1. Our systom is a standard unit that consists of a sensing unit placed in the vacuum chamber so as to 


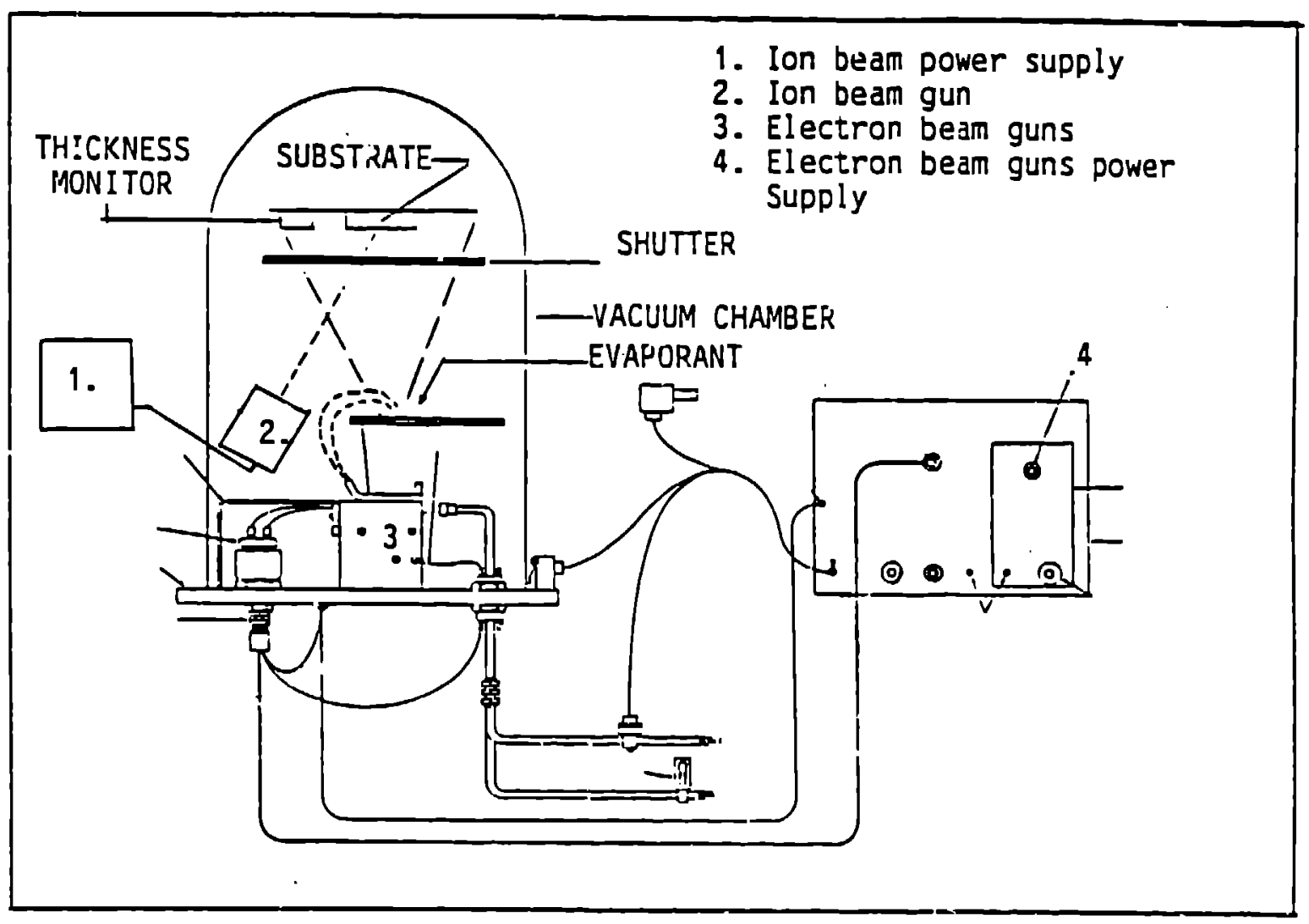

FIGURE 1. Schematic Diagram of the Electron Beam Deposition Technique

be in the avaporant, stream. Deposit buildup on the crystal from the evaporant lowers the ressiant frequency of the crystal. Thus the crystal becomes a highly sensitive mass charge detector ( quartz microbalance teclinique). An oil diffusion pump with a liquid ritrogen trap is used to obtain a base pressure of $10^{-6}$ torr. Oxygen or an oxygen-argon mixture can be admitted through a calibrated leak valve. In order to achieve good quality films for oxide materials, they must be evaporated in the partial pressure of oxygen or some post deposition heat treatment is required. An electron beam evaporation system has a wide range of uses. It is cajable of depositing from 1 to $1000 \mu \mathrm{m} / \mathrm{min}$ onto a surface. Deposition rates above approximately $100 \mu \mathrm{m} / \mathrm{min}$ are considered high rate electron beam evaporation 
(HREBE). HREBE has potential commercial applications for quick large scale coating of substrates. Because the surfaces to be coated will be large, extended vapor sources have to be used. S. Schiller et al. ${ }^{14}$ have obtained high-rate extended vapor sources by use of programmed deflection of a high power beam onto an evaporant contained in a large area crucible. With such high rates, an expanding vapor cloud forms between the evaporant and substrate, making collisions between the vapor particles important. Because the coilisional effacts can be ignored for low rate electron beam evaporation, the physics of HREBE is made more complicated. Furthermore, much of the energy is converted into thermal energy. The power loss, caused by backscatter, depends on mass number of the evaporant as well as angle of incidence of the beam.

\subsection{SPUTTERING TECHNIOUES}

Sputtering is a process whereby a surface is bombarded with energetic particles which causes ejection of surface atoms. The ejected atoins can be condensed into a substrate in the iorm of films. This phenomenon is universal because all kinds of particles can erode all kinds of materials. Figure 2 shows the target efiects that occur due to the bombardment of solids by energetic ions. Ion irradiation can further cause a) radiation damage, b) Jiffusion, c) cascade mixing and d) segregation.

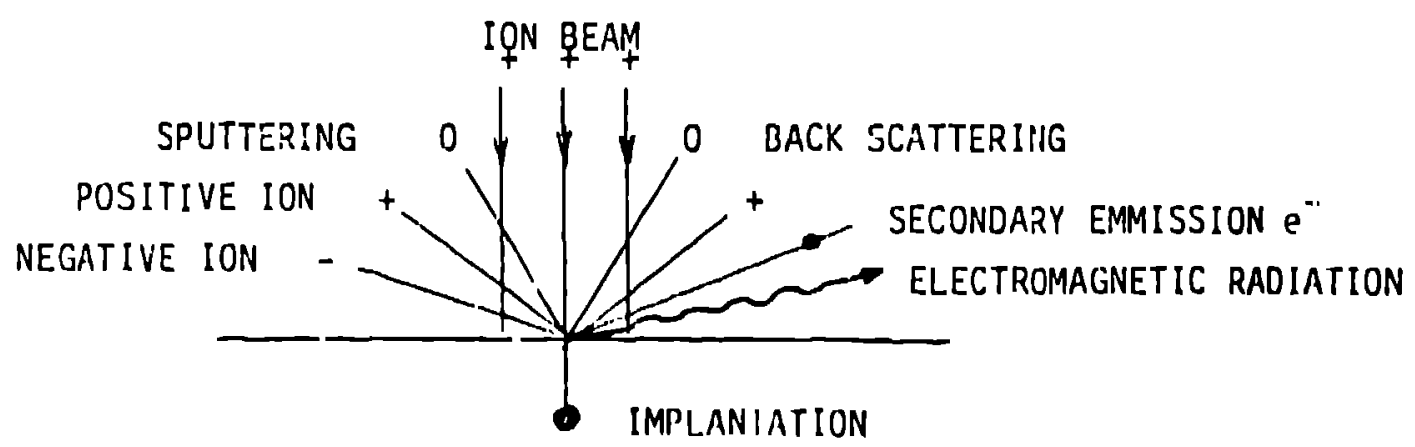

FIGJRE 2. Turdjot Effects Induced by Ion Bombardment of Solids 


\section{page 6}

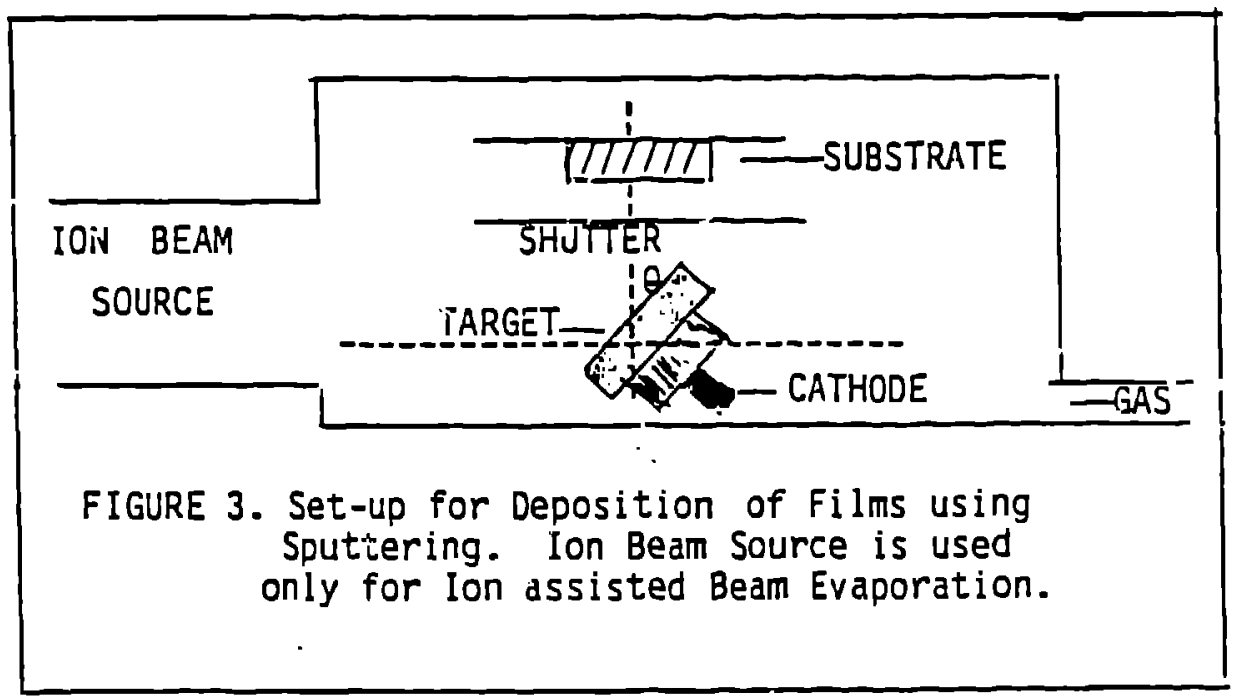

Various sputtering systems such as glow discilarge, reactive, getter, d.c. bias and r.f. sputtering have been employed. Ion beam sputtering and ion slating are commonly employed for thin film Jeposition. Figure 3 shows the basic set-up for sputtering. iypical conditions for D.C. sputtering are a rathode voltage 1-3 kev, cathode current density of 1 to $3 \mathrm{mAcm}^{-2}$, ariu working gas pressure of $10^{- \text {? }}$ torr. For $r$ sputtering power $\sim 200 \mathrm{~W}$ to $1 \mathrm{~kW}$ is delivered to the target from an rf generator of up to $13 \mathrm{MHz}$ via an impedance matching network. Predeposition sputtering is essential in order to clean the surface of the target. Many workers have utilized this technique to grow high qualliy transparent conducting fiims. Minama et a ${ }^{11}$ have used the ULVAC-SBR1104 apraracus and have noticed that superionic cuiducting gidss plates were cracked during the repetition of sputtaring and found that powders were more favorable as target materials. In D.C. and $\mathrm{rf}$ sputtering, high temperatures are created on tha substraice. In cases where a crystalline substrate has a low melting temperature, the magnetron sputtering technique is more suitable, since the heating effect Is substantially reducad. 


\subsubsection{MAGMETRON SPUTTERING ${ }^{16}$}

Film preparation of conducting transparent films of semiconducting oxide materials have been recently tried by magnetron sputtering. This process significantly increases the deposition rate by employing a magnetic field to confine the electrons to a region close to the target surface. Preventing extremely high temperatures can be inportait: in producing amoriphous forms.

\subsubsection{ION BEAM SPUTTERING ${ }^{8}$}

Ion beam sputtering differs from conventional plasma sputtering because tile projectiles borbarding the target are generated in external ion sources. The importance of this technique is that adherrence of ion beam sputtered films is generally superior to that of films deposited by other methods. G. Gautherin et al. ${ }^{17}$ have verified this feature on various metal ilims, e.g., copper on Teflori compounds, alloys and cermets. As a high vacuum ( $<10^{-6}$ torr) is maintained, almost no recondensation of the sputtered particies on the targets is observed. Hence, changes in the composition which ocsur in the r.f. sputtering of composite targets are found to be negligible with ion beam methods. Weissmantal et al. ${ }^{18}$ have demonstrated the suitability of the method for preparing defined cermet films $\left(\mathrm{Ag}, \mathrm{SiO}_{2}\right)$ within a wide range of composition. Because slight contamination of the films by the sputtered source or wall materials has been detected, it might become recessary to coat the acceleration electrodes of the sources with layer material when very high purity is required. Rüre gas inclusion up to $0.5 \%$ Ar was found on semiconductor films due to implantation of backscattered ions and adsorption of residual gas.

Thus $f a r$, most of the work on ion-beam sputtering has been done with ion sources that are capable of prociucing $5-25 \mathrm{~mA}$ of ion current at energies between 1 and 25kcV. This allows unifurm deposition on a substrate area of the order of $10 \mathrm{~cm}^{2}$ at rates of about 100 to $1000 \mathrm{~mm} / \mathrm{min}$. Obviously, for industrial applications much higher areas and deposition rates would be 
page 8

required. P. J. Martin et al. ${ }^{19}$ have used ion assisted deposition as a means of producing thin $\mathrm{ZrO}_{2}$ films ( see fig.3, S.U. system). Film packing density did indeed improve from 0.83 to unity for the dielectric film. The influence of the ion on the film formation can be from substrate cleaning, morphoiogical changes and stimulation of expitaxial growth.

\section{CHEMISAL DEPOSITION METHODS}

When discussing films deposited by chemical methods, two methodological groups can be defined 1) chemical formaton of films from the medium ( e.g. electroplating, chemical reduction plating and vapor phase deposition) and 2) formation of films from substrate (e.g. anodization). the hemical vapor deposition technique is widely used to grow transparent thin film conducting coatings. A schematic of the set-up is shown in figure 4 . The size of the substrate is normally small in order to produce uniform coatings. The temperature of the hotplate can be adjusted. Also the organometallic compounds are kept in a separate container which is surrounded by a liquid bath, the temperature of which can be controlled. A. Learn et al. ${ }^{20}$ have deposited tunsten films using a low pressure chemical vapor deposition technique with a vertical flow reactor. Hydrogen and $W_{6}$ were used as reactants and were separately injected into the deposition chamber. Single crystal silicon wafers of [100] orientation and 30-50 cm resistivity ( $p$-type) were used as substrates for deposition. Blocher and Kalbskoff have further extended the CVD technique to deposit continuous transparent conducting coatings onto glass ribbons. Very uniform coatings were obtained.

Substrate preparation determines the surface properties and these are directly or indirectly related to the film formation of stages of adatoms, interface formation, nuclastion, and film properties such as adhesion, pinhole density, porcsity, film microstructure, morphology and mechanical properties. One must be ver; careful in salecting a particular deposition technique. As an example, the molecular beam epitaxy method has been applied to growing very large, uniform single crystals but is 
extremely sensitive to surface preparation of the substrate.

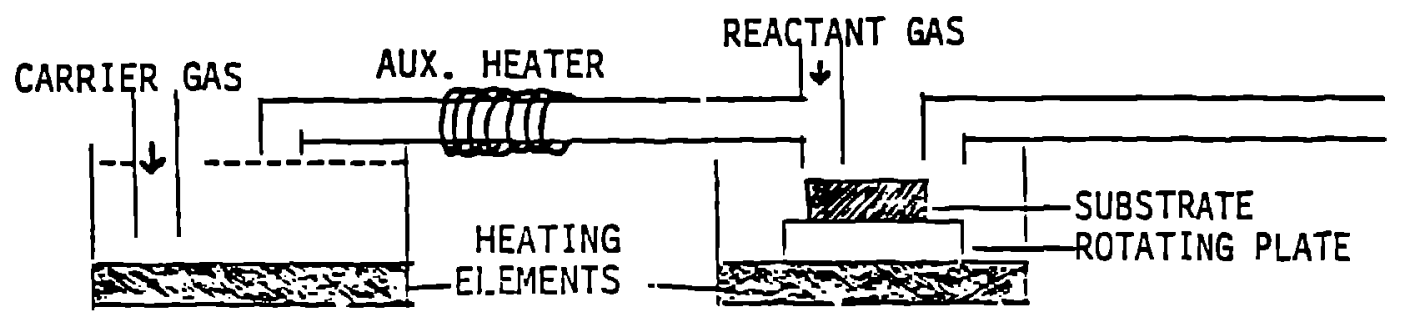

FIGURE 4. Schematic Diagram of the Chemica! Vacor Deposition System

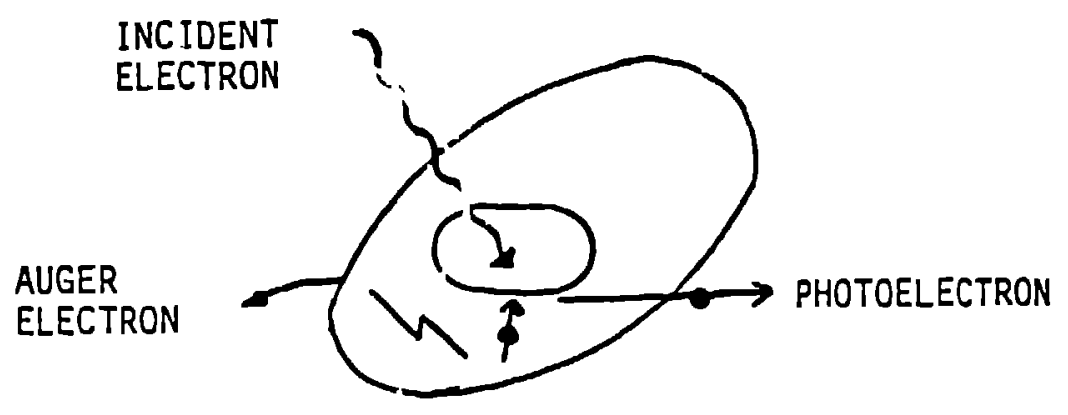

FIGURE 5. Schematic Representation of the Ejection of a Photoelectron with subsequent ejection of an Auger electron.

\section{SURFACE ANALYSIS TECHNIOUES}

Some of the surface analysis techniques capable of analyzing thin films as to their structures are shown in table 1 . It has becorne possible to obtain information decribing the internal structure of films and spec'llate on the mechanisms providing spectrally selective behavior. We shall deal the two important surface analysis techniques, $x$-ray photoelectron spectroscopy (xps) and auger electron spectroscopy (AES). XPS is very surface sensitive, liseful for inorganic, organic, organo-metallic polymeric compounds and measures atomic compositions and chemical environment of the top few atom layers. Fig 5 shows the schematic representation ci how an $x$-ray causes ejection of a photoelectron along with subsequent ejection of an Auger electron. The incoming $x$-ray knocks one cf the electrons out of the atom. The energy of the photoelectron is equal to the energy of the incident $x$-ray minus the binding energy of the electron. This binding 
energy depends on the identity of the element and the chemical environment in which it exists. Any electroin with binding energy less than tine energy of the $x$-ray can je: krlocked out. If the electron is one of the inner shell electrons as suggested by the figure 4 , anotner phenomenon also occurs; the vacancy left by the ejected photoelectron can be fillad by an electron from a higher energy shell with the resultant ejection of an Auger electron. These Auger electrons also appear in the XPS spectrum and often provide useful information. Since the electrons in the outside orbitals are those involved in chemical binding, photoelectrons from outer shells and Auger electons often provide more chemical information than electrons from core levels.

XPS produces little damage to the material. Usually escape depths depend on the energy of the electron and fall in the range 4-30A. Tompkins et. al. 21 have analyzed the spectrum of copper dipped in BIMDA (Benzimidazole) with iriteresting results.

Auger electron spectroscopy ( in which excitation energy is provided by an electron) is useful for metals and oxides but has little use in organic and polymeric materials. In order to investigate the surface structures and depth profiles in metalic crystals, we have established an analysis system that incorporates Auger electron spectroscopy and Low energy electron diffraction (LEED) at our Department under the contract from Los Al amos National Laboratory, U.S.A.. Indeed our group (WEC) has studied the surface structure of $\mathrm{Ni}$ single crystals.

\section{GRAIN BOUNDARY INFLUENCES}

While growing thin films via evaporation and other techniques, varying size grains will be produced. These grain boundaries serve as localized points in the films for a depletion of matter and have been illustrated by considering electromigration induced failure by edge displacement in the fine line Al-Cu thin film conductors ${ }^{22}$. This pilenomena could in time cause changes in resistivity of varying thin films. A.J. Learn ${ }^{20}$ et al have also studied the consequence of grain boundaries in chemical vapor deposited 
tungsten films and concluded that oxygen, located predominantly at the grain boundaries, was a principal determinant of boundary scattering. Impurities (reactive aysrits) in the film may prererentially form at boundary grain boundaries and affect resistivity and other physical properties of the film.

K.D. Krever et al. ${ }^{23}$ observed enhanced conductance along domain anc' grain boundaries in a fast ionic NASICGN conductor. In most cases the boundary affect is due to an increaed defact concentration in the space charge region, whereas in NASICON, the lattice expansion at interface increases the mobility of the Na charge carrier. This effect is relevant for materials with high concentration of defects and low mobility. However, for naterials with low concentration of bulk defects and high mobility, an jncrease in grain boundary conductivity is expected with the minimization of grain size. The transfer of mobile ions between grains can be hindered as a result of segregation of inpurities for polycrystalline solid electrolytes. Bukin et al. ${ }^{24}$ have studied the influence of grain boundaries on the conductivity of solid electrolyte $\mathrm{Na}_{3} \mathrm{Zr}_{2} \mathrm{Ji}_{2} \mathrm{PO}_{12}$ and have shown strong dependence on the resistance of the phase boundaries at low temperatures.

\section{CONCLUSIONS}

An attempt has been made to present some of the thin-film deposition and surface analysis techniques which may be useful in growing superionic conducting materials. Emphasis is made on the importance of being careful in selecting process parameter's and materials in order to produce films with properties outlined in this aticle. Also, special care should be given to proper consideration of grain boundary effects.

ACKNOWLEDGEMEN1:: The authors thank Los Alamos National Laboratory, contract \# 9-X33-L0151-1, for their support in e.itablishing the surface 


\section{page 12}

physics laboratory at Southern University. We acknowlege the Department of the Army for partial support to our research. BRB thanks both the Department of the Army and Los Alamos National Laboratory for providing post doctoral fellowship assistance. We also thank Mrs. J. P. Collins and Joseph Stewart for tneir assistance in preparing this manuscript. 


\section{REFERENCES}

1) P. Vashishta, J. Mundy and G. R. Shenoy "Fast Ion Iransport in Solids, Electrodes, and Electrolytes" Proc. Int. Con on Fast Ior Transport in Solids, Lake Geneva, Wisconsin, May 21-25 1979, North-Holland.

2) B. B. Owens "Solid Electrolyte Batteries" in advances in Fiectrochemical Engineering vol 8. C. W. Tobias ed (John Wiley and Sons, Inc., New York (1971) pp 1-62

3) G. C. Farrington and W. L. Roth in "Superionic Conductors" ed. G. D. Mahan and W. L. Roth plenum (1976)

4) J. B. Boyce and B. A. Huberman "Super Ionic Conductors, Transitions Structures, Dynamics" Phys. Reports 51, N04 (1979) 189-265 North Holland

5) T. Takahasi and Y. Yamato. J. Appl. Electro Chem $\underline{3} 129$ (1973)

6) D. S. Campbell, Thin Solid Films, 32 (1976) 3-10

7) D. L..Dawar, J..C. Joshi, J. Mater. Sci. 19 (1984) 1-23

8) Zbigniew W. Kowalski, J. Mater. Sci. 20 (1985) I521-1555

9) D. M. Mattox, Thin Solid Films, 124 (1985) 3-10

10) G. G. Tompkins, Thin Solid Films, 119 (1984) 337-348

11) Tsutomu Minami and Hiromitsu Kaneko, Solid State Ionics 17 (1985) 57-62

12) S. Kulaszewi.cz, Thin Solid Filns, 74 (1980) 211

13) R. Ponmier, C. Gril and J. Maruccni, Thin Solid Films 77 (1981) 91

14) S. Schiller, G. Jaesch, M. Neumann, Thin Solid F1lms 110 (198.3) 149-16/4

1.5) M. T. Robinson, in "'lopics ir Applied Physics" Vol 1 edited by R. Behrish (Springer, Berlin, 1981) pp 73-144

16) K. Suzuki, M. Mizuhasi, H. Sakata, J. Vac Soc Jpn 2.1 (1978) 158

17) G. Gautherin and CHR. Weissmantel, Thin Solid Films, 50 (1078) 135-144

18) Chr. Welssmante1, M. Rost, 0. Fiedler, H. J. Erder, H. Giegengack and J. Horn. Proc. 6th Vacuum. Congr Kyoto, 1974, in J Jn. J. Appl. Phy. Suppl 2, Part 4, 1974

19) P. J. Martin, R. P. Nettorfield and W. G. S.ainty, J. Appl. Phys. 5542351139

20) A. J. Learn, J. Electrochem. Soc. 137, 390 (1985), J. App1. Phys vo1. 58, No. 5, 1985

21) H. J. Tompkins, Thin Solid Films, 119 (1984) 337-348

22) A. T. English and E. Kinsbron, J. App1. Ph:s. 54 (1) 1983. 268

23) K. D. Kreuer, Mate Res. Bull. Vol. 21 pp 149-159, 1986

24) N. G. Bukin, E. A. Uleshe, E. I. Moskivina, and A. E. Ukshe, Suviet Electrochemist, Vol 2, No. 2, pp 269, 5513 